\title{
PENGUJIAN KUALITAS WEBSITE DITINJAU DARI PERSPEKTIF ACCESSIBILITY, EXPERIENCE, MARKETING DAN TECHNOLOGY
}

\author{
Diyurman Gea \\ Information Systems Department, School of Information Systems, Binus University \\ Jl. K.H. Syahdan No. 9, Palmerah, Jakarta Barat 11480 \\ diyur@binus.edu; diyur@yahoo.com
}

\begin{abstract}
The purpose of this study was to determine the quality of the websites managed by individuals, companies and governments. The test results would be useful for managers to pay more attention to the quality of the website optimally through several perspectives: accessibility, experience, marketing and technology. The research used samples from 350 websites and the data were divided into seven categories, namely: website managed by SMEs (small and medium), website of universities, website of governments, e-commerce, news websites, website of industrial companies, and website of non-profit organization. We used Nibler as the testing tool to facilitate the assessment process. Data were analyzed using WEKA presented in the form of a decision tree. The results showed that the tested websites had an average value of 4.66 or worse (scale 1-10). The conclusion is that the manager of the website should perform repairs on the data and applications, in particular in the perspective of technology, accessibility and experience.
\end{abstract}

Keywords: evaluation, website quality, technology, accessibility and experience

\begin{abstract}
ABSTRAK
Tujuan penelitian ini adalah untuk mengetahui kualitas website yang dikelola secara perorangan, perusahaan dan pemerintah. Hasil pengujian akan berguna bagi pengelola website untuk lebih memperhatikan kualitas secara optimal melalui beberapa perspektif, yaitu: accessibility, experience, marketing dan technology. Penelitian dilakuan pada 350 website dan yang dibagi dalam tujuh ketegori, yaitu: website milik UKM (usaha kecil menengah), website universitas, website pemerintah, website e-commerce, situs berita, website perusahaan industri, dan website organisasi non-profit. Alat bantu pengujian untuk memudahkan proses penilaian adalah Nibler. Data dianalisis menggunakan WEKA yang dipresentasikan dalam bentuk pohon keputusan. Hasil penelitian menunjukkan bahwa website yang dilakukan pengujian memiliki nilai rata-rata 4.66 atau buruk (skala 1-10). Dari hasil penelitian, kami menyimpulkan bahwa pengelola website harus melakukan perbaikan pada data dan aplikasi, khususnya pada perspektif technology, accessibility dan experience.
\end{abstract}

Kata kunci: pengujian, kualitas website, technology, accessibility, experience, marketing 


\section{PENDAHULUAN}

Aplikasi web adalah aplikasi yang dapat diakses melalui jaringan internet dan intranet. Aplikasi ini dapat menampilkan berbagai bentuk informasi seperti teks, gambar, audio dan video. Namun, kalau diperhatikan ada banyak website yang tidak memperhatikan tata letak, manajemen konten yang tidak baik dan penggunaan teknologi yang belum tepat sehingga pengunjung tidak tertarik atau tidak menemukan konten yang dicari pada mesin pencarian. Akibatnya, pesan yang ditampilkan tidak sampai kepada orang-orang yang membutuhkannya. Semakin banyak tawaran menarik dari jasa web design bermunculan untuk menciptakan berbagai macam aplikasi website yang menggunakan teknologi yang cepat, akurat, dan mudah digunakan oleh pengguna. Tentunya, teknologi yang berkualitas baik memerlukan tahapan prosedur yang jelas dan dapat memberikan kepuasan terhadap konsumen.

Kegagalan sebuah aplikasi website tidak saja disebabkan oleh konten yang tidak baik, tapi juga karena dukungan teknologi infrastruktur. Harus diakui bahwa kesiapan infrastruktur komunikasi seperti di Indonesia masih terbatas di daerah perkotaan saja. Tak heran jika Pemerintah Indonesia pernah gagal mengadakan uji kompetensi para Guru di Indonesia secara online pada tanggal 30 Juli 2012, yang disebabkan oleh accessibility atau kondisi koneksi internet di sekolah dengan panitia pusat di Jakarta tidak berjalan mulus (Tempo, 2012).

Kemudahan penggunaan sistem yang dibuat pun sering diragukan. Seorang peneliti yang melakukan pengujian terhadap pengoperasian dan penggunaan aplikasi situs e-government di Indonesia, menunjukkan hasil kalau secara rata-rata penggunaannya sangat sulit bagi karyawan wiraswasta, ibu rumah tangga, pengangguran ataupun para pensiunan. Secara visual, situs pemerintah memang sulit bagi orang-orang yang berusia di atas 41 tahun atau di bawah 20 tahun (Dahlan, 2010). Hal ini juga mencerminkan lemahnya tingkat experience pengguna dalam mengoperasikan sistem.

Popularitas sebuah website dipengaruhi oleh peningkatan jumlah pengunjung melalui pemanfaatan intelijen berbasis web yang multichannel (Stanhope, 2010). Developer sistem harus mampu menciptakan kreatifitas dan inovasi baru sehingga unik, memperbanyak tautan dengan situs yang lain, serta terhubung dengan jejaring sosial. Sebanyak 29\% dari 220 juta pelanggan telpon seluler di Indonesia adalah melakukan akses internet melalui handphone (Rao, 2012). Hal ini memberi harapan baru kepada perusahaan dalam hal pemanfaatan alat komunikasi telpon sebagai media marketing untuk penyampaian informasi produk bagi pelanggan. Kerena keterbatasan kemampuan handphone atau smartphone dibandingkan dengan komputer, maka penyusunan konten dan bobot materi harus memerlukan penyesuaian.

Sebelum para pengembang merilis aplikasi yang telah dibangun, akan lebih baik apabila aplikasi tersebut sudah melalui prosedur pengujian. Sistem pengujian merupakan suatu tahap yang digunakan untuk mendeteksi apakah terjadi kesalahan yang belum terungkap (Gea, 2011). Dengan adanya pengujian akan mengungkap kondisi sebuah aplikasi apakah masih memiliki kekurangan dan telah dibangun sesuai persyaratan yang telah disusun sejak awal (Meier, 2007). Tidak hanya mendeteksi kesalahan, pengujian juga berfungsi untuk mengetahui apakah aplikasi tersebut sudah sesuai dengan keinginan pengguna dan berfungsi dengan spesifikasi yang diinginkan serta berbagai kekurangan lain yang akan mengganggu jalannya aplikasi website.

Berdasarkan uraian masalah tersebut diatas, pengujian terhadap Accessibility, Experience, Marketing dan Technology sangat diperlukan untuk menjamin bahwa produk aplikasi yang dihasilkan sudah mampu menghasilkan output yang diharapkan. 
Penelitian ini didasarkan pada laporan The Indonesia Competitivenes Report 2012 yang melakukan pengukuran kepada 142 negara di dunia. Indonesia berada pada peringkat 80, turun jauh dari peringkat 53 di tahun sebelumnya, dan atau urutan ke-5 dari urutan Negara-negara ASEAN (WEForum, 2012). Dari 12 variabel pengukuran yang digunakan, salah satunya adalah kesiapan pemanfaatan teknologi. Dalam tulisan ini, penelitian dilakukan pada kesiapan pemanfaatan teknologi website melalui pengujian kualitas website, dan yang dilihat dari perpektif Accessibility, Experience, Marketing dan Technology. Ke-empat perspektif tersebut adalah juga variabel yang digunakan dalam alat bantu pengujian Nibler.

Tujuan dari penelitian ini adalah mengetahui unsur apa saja yang dominan mempengaruhi kualitas dari beberapa website yang ada di Indonesia, sehingga masing-masing pemilik website dapat melakukan perbaikan pada sistem yang lebih baik. Karena pada dasarnya, pengujian dilakukan untuk mengurangi resiko dari kesalahan sistem. Kesalahan menyebabkan kerugian dan kerugian identik dengan kehilangan. Walaupun resiko adalah sesuatu yang tidak pasti terjadi dan terkadang menjadi suatu yang tidak dapat dihindari, tetapi harus ada tindakan nyata untuk meminimalkan atau menghilangkan dampak dari resiko tersebut.

\section{METODE}

Pengujian sebuah sistem bertujuan untuk mengetahui apakah sistem dapat bekerja dibawah beban kerja yang biasanya meliputi test ketanggapan, kehandalan, stablititas dan skalabilitas (Microsoft, 2007). Pengujian ini pada umumnya dilakukan untuk mengevaluasi kinerja, melakukan perbandingan kinerja sistem untuk menentukan mana yang lebih baik dan menemukan sumber masalah yang terjadi pada sistem.

Pengujian kinerja meliputi tiga kategori sebagai berikut: (1) pengujian performance, yaitu menguji kecepatan validasi, skalabilitas, kestabilan sistem yang diuji; (2) load testing, yaitu menguji kecepatan performa sistem yang diuji ketika sedang dibawah kondisi tertekan selama proses sistem bekerja; (3) stress testing, yang berfokus kepada menentukan atau memvalidasi kinerja sistem yang diuji ketika sedang dibawah tekanan, dan volume tekanan yang berada diluar antisipasi sistem. Pengujian ini berguna untuk mengetahui apakah sistem akan gagal berdasarkan indikator benchmark yang diuji.

Pengujian sebuah aplikasi akan lebih mudah jika menggunakan perangkat alat bantu. Alat bantu pengujian yang digunakan sangat beragam, tergantung dari maksud dan tujuan dari pengujian itu sendiri. Untuk sebuah website, variabel yang biasa dilakukan untuk menilai apakah sebuah website baik atau tidak, dapat diukur dari accessibility (Cryan, 2012), experience (Kelleher dan Peppard, 2010), marketing (NTDA, 2012) dan technology (Panda, 2012).

Pengujian pada penelitian ini dilakukan pada situs website yang dimiliki oleh Indonesia, yang dikumpulkan secara acak. Karena data yang dikumpulkan adalah data sampel yang memberi peluang atau kesempatan tidak sama bagi setiap unsur atau anggota populasi untuk dipilih menjadi sampel, maka penulis memilih untuk menggunakan teknik Nonprobability sampling dengan target quota sampling yang jumlah datanya 50 website per kategori, dan dianggap cukup untuk mewakili domain yang akan diuji. Pengumpulan sampel data dilakukan secara bebas dari populasi yang mempunyai ciriciri atau kategori tertentu sampai jumlah yang diinginkan (Doherty, 1994). Terdiri dari tujuh kategori website yang akan diuji, yaitu: usaha kecil menengah (UKM), perguruan tinggi, pemerintah, situs berita, industri, e-commerce dan organisasi. 
Dari 567 nama domain yang dikumpulkan, hanya 410 nama domain saja yang diuji karena sisanya tidak bisa diakses. Kemudian, melakukan pengelompokkan nama domain berdasarkan content sebanyak 50 nama domain per kategori, tidak termasuk perusahaan yang menggunakan domain gratis, sehingga 350 situs website yang akan diuji. Pengujian dilakukan selama satu minggu, yaitu pada minggu ke-2 bulan Maret 2013.

Tahapan penelitian ini digambarkan sebagai berikut (Gambar 1).

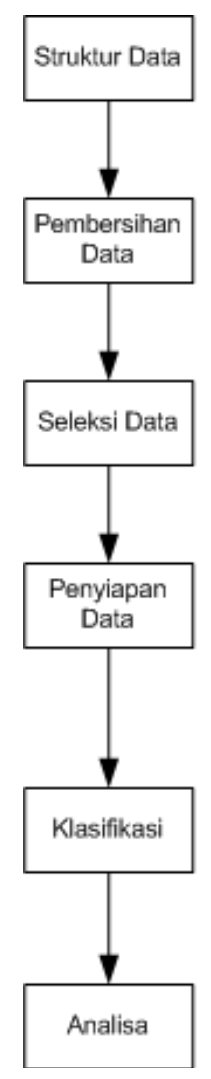

Mengumpulkan daftar nama perusahaan yang ada di katalog yellowpages, dan melakukan pencarian di internet untuk mendapatkan nama domainnya

Melakukan pengujian terhadap domain apakah masih aktif atau tidak

Memisahkan website perusahaan yang menggunakan domain gratis dan domain yang dibeli

Melakukan pengujian terhadap domain yang masih aktif dan dapat diakses

Melakukan pengujian menggunakan tools Nibbler untuk mendapatkan score website.

Melakukan pencatatan score berdasarkan 4 (empat) variabel penilaian yaitu: Accessibility, Technology, Experience, Marketing.

Data disimpan dalam format csv

Data website dikelompokkan berdasarkan bidang usaha yaitu: UKM, Perguruan Tinggi, Pemerintah, Berita, Organisasi, ECommerce, Industri

Score rata-rata dari variabel diklasifikasikan berdasarkan skala: Very Poor (0-2), Poor (3-4), Good (5-6), Very Good (7-8) dan Excelent (9-10)

Melakukan analisis data berdasarkan Pohon Keputusan yang dihasilkan oleh software WEKA dengan Classifiers J48

Gambar 1 Tahapan dan penjelasan metode penelitian

Alat bantu yang digunakan untuk mengetahui score sebuah website adalah Nibbler yang dapat di akses secara online di situs silktide http://nibbler.silk tide.com/. Berbeda dengan alat bantu pengujian website lainnya, fitur yang dimiliki Nibbler lumayan lengkap. Empat variabel utama pengujiannya adalah Accessibility (tingkat kemudahan akses situs), Experience (tingkat kepuasan pengunjung), Marketing (tingkat popularitas situs di search engine), dan Technology (tingkat kesempurnaan desain dan teknologi yang digunakan) (Tabel 1). Selain empat poin tersebut, hal-hal sekunder lainnya adalah printability (kemampuan mencetak), W3C compliance (kesesuaian script dengan standar W3C), Social Media (tingkat popularitas di situs jejaring sosial), kualitas link, popularity (Alexa Rank), meta tags, feed, URL format, dan masih ada lagi variabel pengujian lainnya.

Semua pengujian tersebut dapat dilakukan secara online dengan memasukkan URL situs pada kolom yang tersedia, lalu klik "test". Dalam beberapa saat kemudian, akan muncul semua hasil pengujian tersebut. Nibler menguji website dengan skala nilai 1 hingga 10 . Nilai 1 adalah nilai terendah dan 10 adalah nilai terbaik. Selain menguji, Nibbler juga mencantumkan berbagai saran yang dapat dilakukan oleh pemilik web atau blog berdasarkan hasil tesnya. 
Tabel 1 Kompenen Penilaian pada Variabel Pengujian

\begin{tabular}{llll}
\hline $\begin{array}{c}\text { Technology } \\
\begin{array}{c}\text { How well designed and } \\
\text { built the website is) }\end{array}\end{array}$ & $\begin{array}{c}\text { Marketing } \\
\text { (How well marketed, and } \\
\text { popular the website is) }\end{array}$ & $\begin{array}{c}\text { Experience } \\
\text { (How satisfying the website is } \\
\text { likely to be for users) }\end{array}$ & $\begin{array}{c}\text { Accessibility } \\
\text { (How accessible the website is } \\
\text { to mobile and disabled users) }\end{array}$ \\
\hline $\begin{array}{l}\text { Code quality } \\
\text { Media types }\end{array}$ & $\begin{array}{l}\text { Facebook page } \\
\text { Incoming links }\end{array}$ & $\begin{array}{c}\text { Facebook page } \\
\text { Media types }\end{array}$ & Code quality \\
Server behaviour & Popularity & Popularity & Links \\
Feeds & Feeds & Server behaviour & Headings \\
Links & Links & Feeds & Page titles \\
Headings & Headings & Links & URL format \\
Meta tag & Analytics & Facebook sharing & \\
URL format & Page titles & URL format & \\
& Facebook sharing & & \\
\hline
\end{tabular}

Setelah mendapatkan score masing-masing ke-4 variabel utama tersebut, dilakukan perhitungan rata-rata dan melakukan pengelompokkan berdasarkan skala penilaian pada Tabel 2 . Untuk membantu analisis terhadap data yang diperoleh, peneliti menggunakan software WEKA. WEKA adalah aplikasi Data Mining Open Source berbasis Java, yang terdiri dari koleksi algoritma machine learning yang dapat digunakan untuk melakukan generalisasi/formulasi dari sekumpulan data sampling. Paket algoritma yang digunakan adalah Classifier, yang mendeklarasikan struktur umum dari skema klasifikasi dan prediksi (Rajput, 2011). Untuk membantu penulis dalam pembentukan pohon keputusan, kelas yang digunakan adalah Classifiers J48, yang mengerjakan semua proses konstruksi pohon. Alasan penggunaan WEKA sebagai alat bantu analisis data adalah karena software ini mampu melakukan analisis perhitungan dengan jumlah data yang sedikit, dan mampu membentuk Decision Tree (pohon keputusan).

Tabel 2 Skala Penilaian

\begin{tabular}{ccc}
\hline No & Scale & Description \\
\hline 1 & $0-2$ & Very Poor \\
2 & $3-4$ & Poor \\
3 & $5-6$ & Good \\
4 & $7-8$ & Very Good \\
5 & $9-10$ & Excelent \\
\hline
\end{tabular}

\section{HASIL DAN PEMBAHASAN}

Berdasarkan hasil kompilasi data, didapatkan hasil bahwa komponen utama yang paling penting dari ke-4 variabel yang digunakan oleh alat bantu Nibbler adalah Teknologi sebagai kunci utama keberhasilan penerapan ICT (Butler, 2002). Teknologi tidak hanya mempengaruhi interaksi, tapi juga meningkatkan stabilitas yang berdampak pada berbagai sisi, memberi harapan baru meskipun wujudnya tidak terlihat (Tamarkin, 2010). Berdasarkan skala penilaian (Tabel 2), ternyata dari data yang digunakan sebagai sampel, belum ada website yang excelent atau memenuhi standar yang maksimum. 
7).

Di bawah ini adalah pohon keputusan yang dibentuk berdasarkan kriteria website (Gambar 2 -

\section{Situs Usaha Kecil Menengah (UKM)}

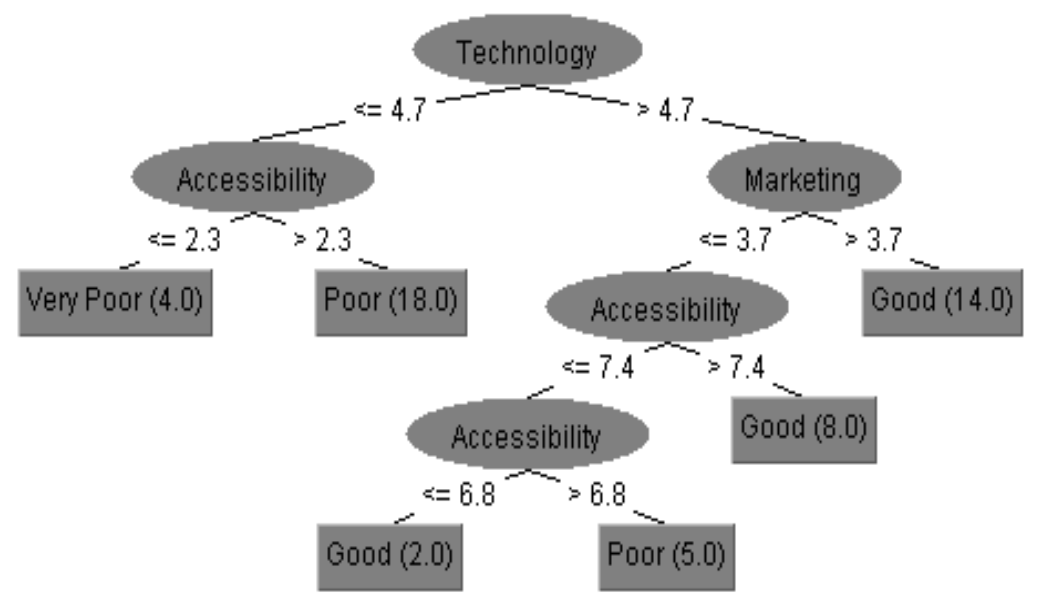

Gambar 2 Pohon keputusan J48 Kategori Situs UKM

Gambar 2 menunjukkan bahwa pemanfaatan teknologi yang lebih baik pada aplikasi website UKM merupakan faktor yang paling berpengaruh pada keberhasilan website perusahaan. Faktor lainnya adalah aksesibilitas pada informasi produk barang. Dengan tersedianya informasi produk pada website, berdampak positif pada kegiatan pemasaran, karena dapat diakses tanpa batas.

\section{Situs Perguruan Tinggi}

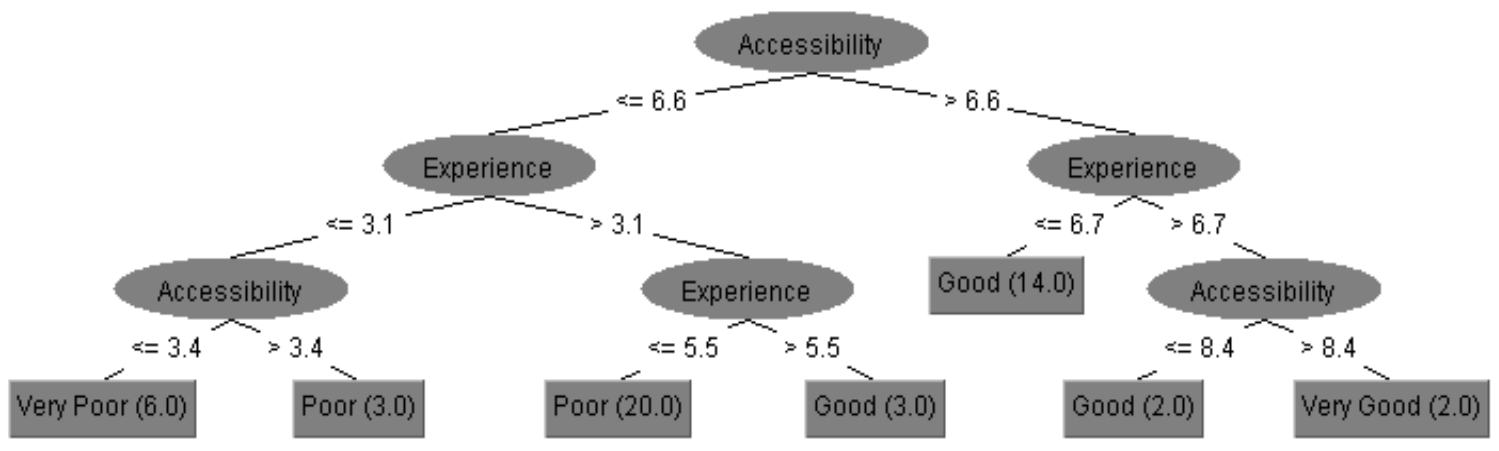

Gambar 3 Decision Tree J48 Kategori Situs Perguruan Tinggi

Aksesibilitas pada Gambar 3 memberi arti bahwa orang dengan keterbatasan (misalnya, pada visual, indra pendengaran, atau kognitifnya) dapat merasa, memahami, menelusuri, dan berinteraksi dengan web. Perguruan tinggi sebagai industri layanan di bidang pengetahuan, harus menyediakan fasilitas atau kemudahan akses untuk mendapatkan materi sebagai sumber ilmu dan pengetahuan, dan mampu berinteraksi dengan nara sumber seperti dosen melalui pemanfaatan teknologi. 


\section{Situs Pemerintah}

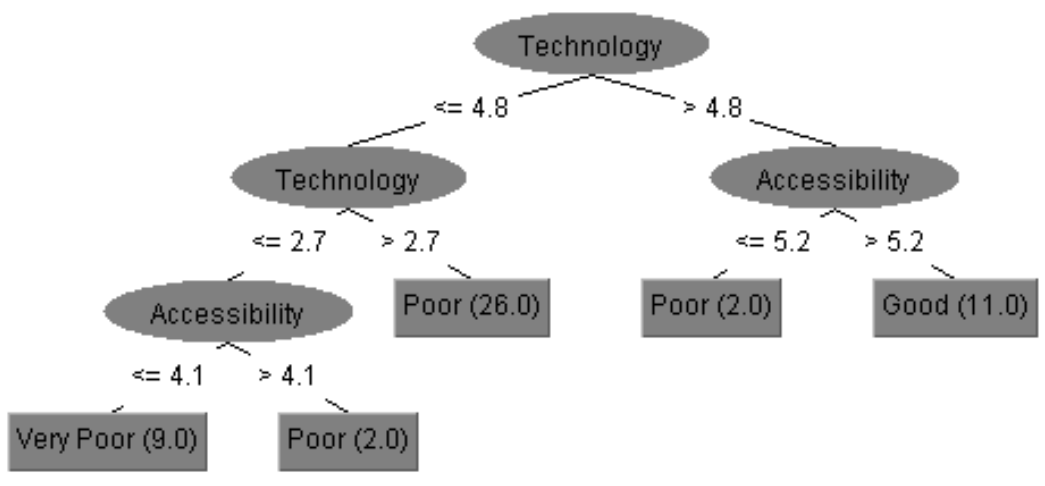

Gambar 4 Decision Tree J48 Kategori Situs UKM

Institusi pemerintah sebagai badan yang memberi pelayanan kepada masyarakat, sudah pasti banyak informasi yang disampaikan kepada publik, misalnya peraturan dan perundang-undangan serta urusan administrasi lainnya seperti Kartu Tanda Penduduk (KTP). Indonesia sebagai negara kepulauan, sudah selayaknya menyediakan teknologi yang memadai untuk menjawab permasalahan di bidang transportasi dan akomodasi. Melalui aplikasi website juga dapat memberikan dampak terhadap lembaga politik, yaitu membantu para wakil rakyat yang bekerja dalam pemerintahan untuk mendapatkan informasi apa yang dibutuhkan dalam masyarakat. Masyarakat yang sekarang cenderung menyuarakan aspirasinya di media website ataupun jejaring sosial akan sangat membantu pemerintah untuk mengetahui dan memonitori suara masyarakat terhadap kebijakan-kebijakan yang dikeluarkan oleh pemerintah. Gambar 3 memberi makna bahwa dengan dukungan teknologi yang memadai, akan memberi kemudahan bagi publik untuk mendapatkan informasi, meskipun berada pada letak geografis yang berbeda.

\section{Situs Berita}

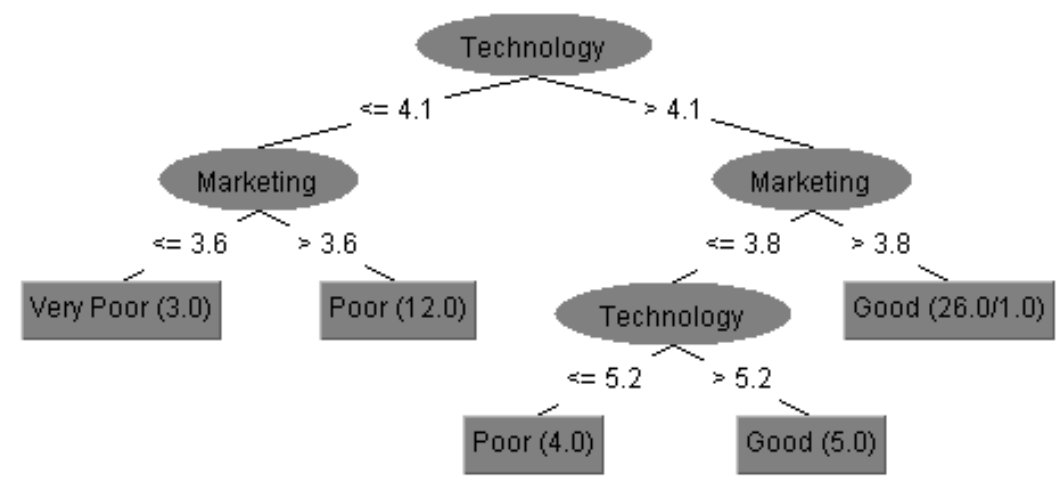

Gambar 5 Decision Tree J48 Kategori Situs Berita 
Website dan social media saat ini bukan hanya sebagai situs untuk menyampaikan berita, atau untuk pertemanan biasa seperti pada umum nya, tapi juga untuk melakukan kampanye untuk memikat berbagai kalangan. Kehadiran teknologi internet telah meningkatkan komunikasi antara orang di seluruh dunia. Setiap orang memungkinkan untuk mengekspresikan diri melalui blog, website, gambar, dan lainnya. Karena itu, dukungan teknologi menjadi hal utama yang harus diperhatikan serta tampilan dan isi informasi yang selalu terbaru sehingga mampu menarik perhatian pengunjung.

\section{Perusahaan Industri}

Pengaruh teknologi informasi secara tidak langsung memberikan solusi yang dapat membantu urusan bisnis secara ringkas dan tidak perlu lagi memakan biaya yang begitu besar. Perkembangan teknologi informasi yang semakin canggih dewasa ini merupakan bagian integral dari semua lapangan bisnis. Mau tidak mau para pelaku bisnis harus bisa mengikuti laju dari perkembangan teknologi informasi agar dapat memenangkan kompetisi bisnis.

Melalui Website perusahaan dapat mengkomunikasikan nilai-nilai produk atau layanan yang dimiliki, sehingga menghasilkan suatu persepsi tersendiri pada diri pelanggan. Hal ini sangat berkaitan langsung dengan kepuasan pelanggan dan customer experience. Ketika customer experience sama dengan ekspetasi atau lebih dari ekspetasi, mereka akan puas. Sebaliknya, jika customer experience lebih buruk dari ekspetasi, maka mereka akan kecewa. Oleh karena itu, yang perlu diperhatikan adalah membangun website yang memberikan customer experience yang sesuai dengan value proposition yang telah disampaikan kepada pelanggan. Hal ini dapat dilihat pada Gambar 6.

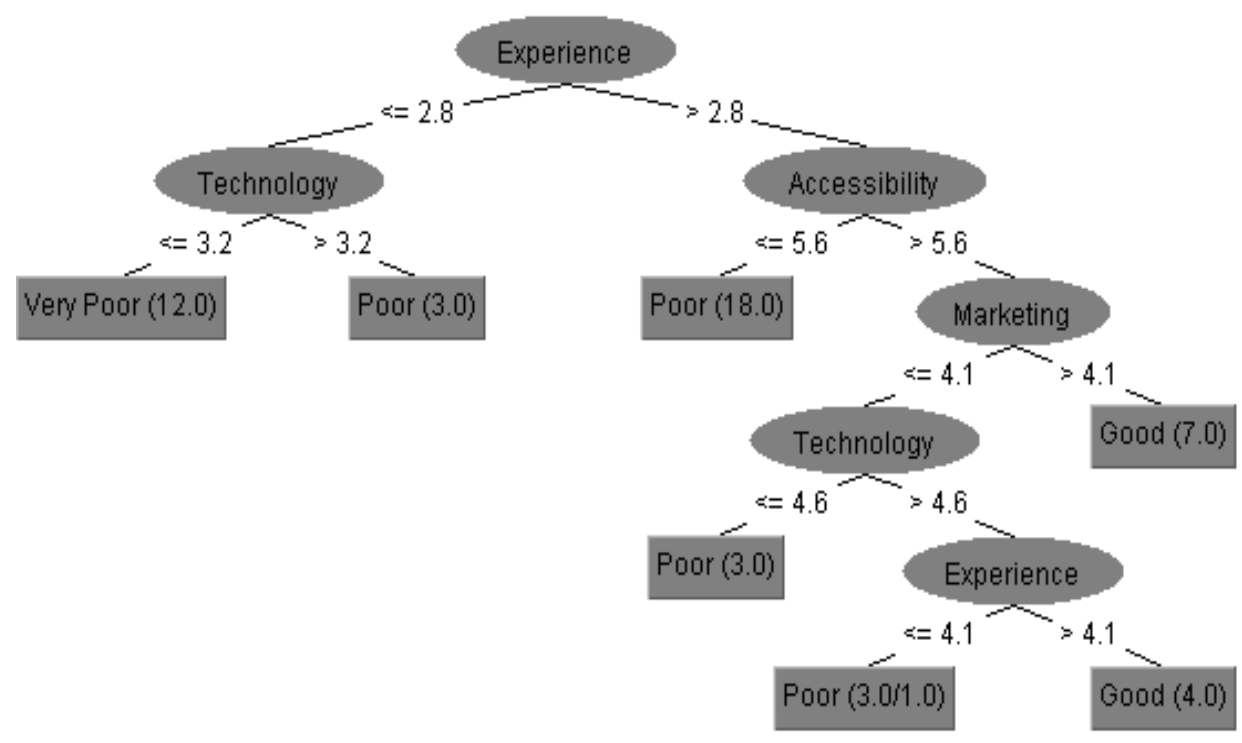

Gambar 6 Decision Tree J48 Kategori Situs Industri 


\section{Situs E-Commerce}

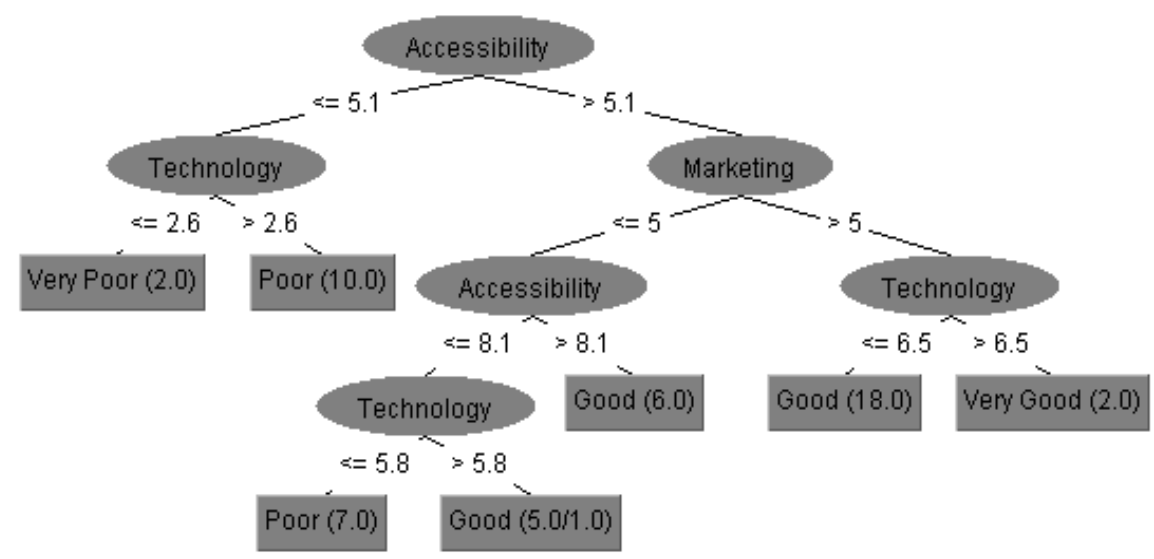

Gambar 6 Decision Tree J48 Kategori Situs E-Commerce

E-commerce menjadi alternatif bisnis di era modern yang sejalan dengan kondisi pasar yang semakin dinamis dan persaingan yang kompetitf, mengakibatkan perubahan pada perilaku konsumen. Gambar 6 menunjukkan bahwa perusahaan harus mengutamakan kebutuhan konsumen yang menginginkan aksesibilitas informasi yang cepat, mengetahui harga di pasaran melalui media website. Kondisi ini menyebabkan website harus memperhatikan kualitas informasi, kualitas sistem, kualitas layanan untuk dapat menciptakan kepuasan konsumen dan loyalitas konsumen. Dengan memanfaatkan teknologi internet, perusahaan dapat melakukan berbagai kegiatan marketing dan transaksi bisnis secara elektronik serta berbagi informasi dengan konsumen dan suplier untuk mempertahankan hubungan sebelum, selama dan setelah proses pembelian. Aktifitas bisnis secara elektronik ini telah memberikan beberapa kemudahan baik bagi penjual maupun bagi pembeli. Bagi pihak penjual, ecommerce akan membantu untuk memperluas daerah pemasaran produk yang akan dijualnya, sedangkan bagi pembeli, akan mempermudah mendapatkan dan membandingkan informasi tentang produk yang akan dibelinya. Maka dari itu perusahaan sangat perlu memperhatikan kualitas layanannya agar dapat menciptakan kepuasan konsumen yang diharapkan oleh perusahaan.

\section{Situs Organisasi}

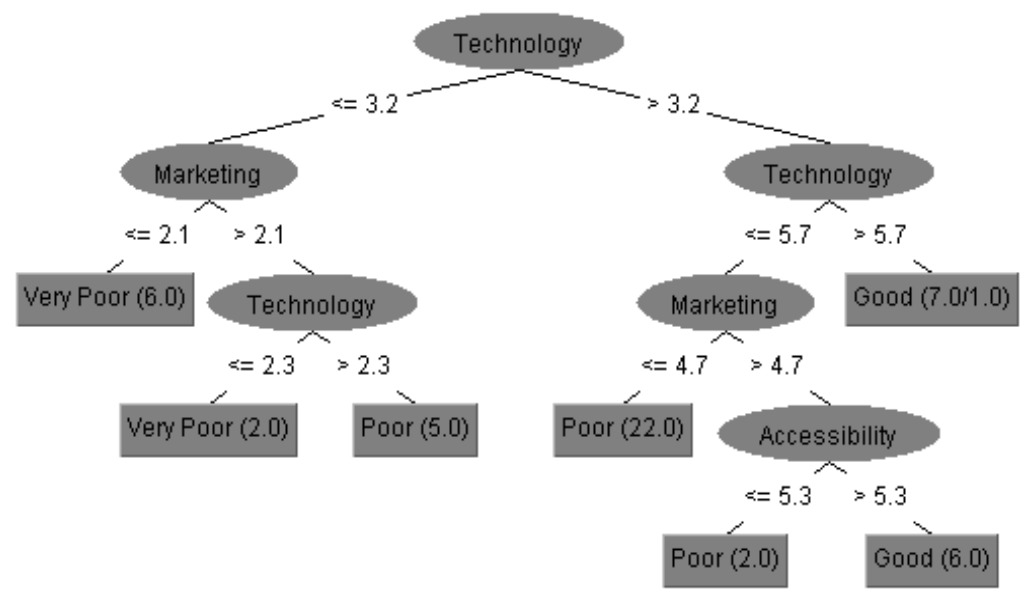

Gambar 7 Decision Tree J48 Kategori Situs E-Commerce 
Internet sebagai media komunikasi dan informasi telah terbukti mampu untuk menghubungkan antara satu orang dengan yang lainnya di berbagai belahan dunia, misalnya menggunakan aplikasi chatting. Gambar 7 menunjukkan hasil pengujian pada website yang dikelola oleh organisasi non-profit, yang dananya sangat terbatas dan hanya mengharapkan uluran tangan dari para donatur, kadang kala pengembangan website hanya dilakukan seadanya dan lebih banyak yang memanfaatkan layanan gratis. Untuk mengoptimalkan layanan website tersebut, maka perusahaan harus memperhatikan unsur teknologi dan pemanfaatan jejaring sosial untuk memperbanyak tautan dan aksesibilitas informasi kepada masyarakat.

\section{Rekapitulasi Data}

Keseluruhan data hasil pengujian disajikan pada Tabel 3 berikut ini.

Tabel 3 Rekapitulasi Data Hasil Pengujian

\begin{tabular}{|c|c|c|c|c|c|c|c|}
\hline \multirow[b]{2}{*}{ Category } & \multirow[b]{2}{*}{$\begin{array}{l}\text { Root of } \\
\text { Problem }\end{array}$} & \multirow{2}{*}{$\begin{array}{l}\text { Correctly } \\
\text { Classified } \\
\text { Instances }\end{array}$} & \multirow{2}{*}{$\begin{array}{c}\text { Incorrectly } \\
\text { Classified } \\
\text { Instances }\end{array}$} & \multicolumn{4}{|c|}{ Dependent Variable in the Tree } \\
\hline & & & & $\begin{array}{c}\text { Technolo } \\
\text { gy }\end{array}$ & Experience & Marketing & Accessibility \\
\hline UKM & Technology & $78.4 \%$ & $21.6 \%$ & $\mathbf{v}$ & $\mathbf{x}$ & $\mathbf{v}$ & $\mathbf{v}$ \\
\hline Pemerintah & Technology & $84 \%$ & $16 \%$ & $\mathbf{v}$ & $\mathbf{x}$ & $\mathbf{x}$ & $\mathbf{v}$ \\
\hline Berita & Technology & $90 \%$ & $10 \%$ & $\mathbf{v}$ & $\mathbf{x}$ & $\mathbf{v}$ & $\mathbf{x}$ \\
\hline Organisasi & Technology & $70 \%$ & $30 \%$ & $\mathbf{v}$ & $\mathbf{x}$ & $\mathbf{v}$ & $\mathbf{v}$ \\
\hline Perguruan Tinggi & Accessibility & $66 \%$ & $34 \%$ & $\mathbf{x}$ & $\mathbf{v}$ & $\mathbf{x}$ & $\mathbf{v}$ \\
\hline E-Commerce & Accessibility & $70 \%$ & $30 \%$ & $\mathbf{v}$ & $\mathbf{x}$ & $\mathbf{v}$ & $\mathbf{v}$ \\
\hline Industri & Experience & $72 \%$ & $28 \%$ & $\mathbf{v}$ & $\mathbf{v}$ & $\mathbf{v}$ & $\mathbf{v}$ \\
\hline
\end{tabular}

Keterangan:

$\mathrm{v}=$ variabel persepsi yang harus diperbaiki

$\mathrm{x}=$ variabel persepsi yang sudah bagus sehingga tidak disyaratkan untuk diperbaiki

Tabel 3 di atas memberi informasi bahwa variabel experience tidak selalu berpengaruh pada kategori bidang usaha. Khusus untuk kalangan industri, semua variabel sangat berpengaruh, dan yang paling berpengaruh adalah variabel experience. Dari ke-7 kategori website yang diuji, yang menjadi akar utama yang mempengaruhi sistem penilaian pada website adalah technology, accessibility dan experience. Keakuratan alat bantu dalam melakukan pengujian, lebih dari $60 \%$ sehingga data yang diuji memberi informasi tingkat kepercayaan yang besar kepada pembaca.

\section{PENUTUP}

Dengan semakin meningkatnya pertumbuhan layanan internet, yang penggunaannya untuk tujuan e-commerce, organisasi, baik di sektor business-to-consumer (B2C) dan business-to-business (B2B), telah membuktikan adanya peningkatan layanan terhadap pelanggan dan yang mempengaruhi peningkatan keuntungan perusahaan. Namun, sedikit perusahaan yang memperhatikan faktor-faktor yang mempengaruhi pencapaian tujuan tersebut. Dari 350 website yang diuji, rata-rata score yang diperoleh adalah 4.66 atau poor (jelek). Penilaian tersebut didasarkan pada kemampuan technology, accessibility, dan experience yang masih lemah. Setiap perusahaan memiliki karakterisitik yang berbeda, tergantung dari kategori perusahaannya. Sehingga cara penyelesaian masalahnya akan berbeda. Untuk lebih detil mengenai komponen variabel yang menyebabkan penilaian websitenya menjadi kecil, dapat menggunakan tool Nibbler. Hasil penelitian ini memberikan informasi yang jelas bahwa pengujian situs web harus dilakukan sebelum merilis ke publik. Tujuannya agar pihak developer melakukan proses penyempurnaan dengan mengikuti praktek-praktek terbaik yang sudah pernah ada, dan melakukan inovasi baru. 


\section{DAFTAR PUSTAKA}

Butler, Darrell L., Sellbom, M. (2002). Barriers to adopting technology for teaching and learning. Educause Quarterly, 2.

Cryan, Michele (2012) Understanding web accessibility from the user's perspective. Social Advocacy and Systems Change Journal, 3 (1).

Dahlan, Nariman (2010) Correspondence Analysis of Indonesian e-government websites. Ritsumeikan journal of Asia Pacific Studies, 28.

Doherty, M. (1994) Probability versus non-probability sampling in sample surveys. The New Zealand Statistics Review, March Issue, 21-28.

Gea, Diyurman (2011) Analisis pengujian optimalisasi kinerja website. Seminar Nasional Aplikasi Teknologi Informasi 2011, Yogyakarta.

Kelleher, C. and Peppard, Joe. (2010) The Web Experience: Trends in e-Service,. Diakses April 9, 2013 dari website Cranfield School of Management: http://www.som.cranfield.ac.uk/som/dinamiccontent/media/ISRC/The\%20web\%20experience\%20-\%20trends\%20in\%20eservice.pdf.

Microsoft. (2007). Performance Testing Guidance for Web Applications. Microsoft Press.

NTDA. (2012) Overview of Internet Marketing. Failte, Ireland: National Tourism Development Authority.

Panda, Siba P. (2012) Web technology: its role and importance in library and information science. VSRD Technical and Non-Technical Journal, 3(4).

Rajput, A., Aharwal, Ramesh P., Dubey, M., Saxena, S.P., Raghuvanshi, M. (2011) J48 and JRIP rules for e-governance data. International Journal of Computer Science and Security (IJCSS), 5 (2).

Rao, Madanmohan. (2012). Crossroads of innovation. Mobile Southeast Asia Report 2012.

Stanhope, Joseph. (2010). How Web Analytics Will Emerge as a Cornerstone of Customer Intelligence: Using Site-Based Intelligence to Drive Multichannel Marketing Improvements. Cambridge: Forrester Research.

Tamarkin, Molly (2010) The Most Important Evolving Technology. Educause Review November/December 2010

Tempo. (2012). Server Ngadat Lagi, Uji Kompetensi Guru Gagal. Diakses dari website Tempo: http://www.tempo.co/read/news/2012/07/30/079420220/Koneksi-Buruk-Guru-Gagal-Ikut-UjiKompetensi.

WEForum. (2012). The Global Competitiveness Index 2012-2013 data platform. Diakses April 9, 2013 dari http://reports.weforum.org/global-competitiveness-report-2012-2013/. 